\title{
Conjugating a Cyanine Dye to a Polymer Surface. In Search of a Monomeric Dye in Apolar Media
}

\author{
Fabrizio Pertusati and Fredric M. Menger* \\ Department of Chemistry, Emory University Atlanta, GA 30033, USA \\ menger@emory.edu
}

Supporting Information

\section{Table of contents}

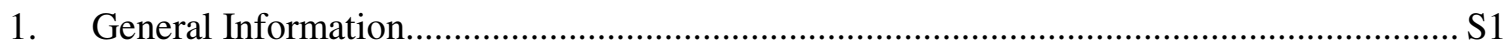

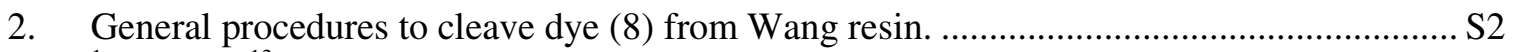

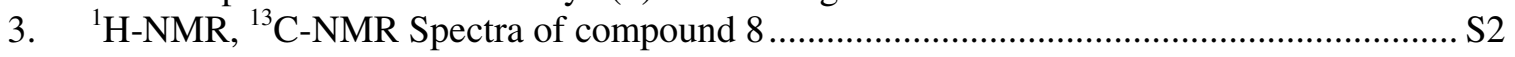

\section{General Information.}

All reagents were of the highest purity available. Solvents were of analytical grade. Methanol, acetonitrile and pyridine were dried over $3 \AA$ molecular sieves, one day prior to use. All NMR spectra were recorded on a $600 \mathrm{MHz}$ instrument. Chemical shifts $(\delta)$ are given in ppm and coupling constants $(J)$ in $\mathrm{Hz}$.

Merrifield resin (1.1 mmol/g, 200-400 mesh, 2\% DVB, batch A32106) and chlorinated Wang resin (benzyloxybenzyl chloride polymer bound, 100-200 mesh, 1\% cross-linked with DVB, $1.1 \mathrm{mmol} / \mathrm{g}$ ) were used as received. Solid phase reactions were conducted in regular flasks and were agitated by gentle (interval) stirring with a magnetic stirring bar. The standard protocol for work-up involved filtration of the reaction mixture over a P3 glass filter, followed by extensive washing of the resin using several swell and squeeze cycles (dichloromethane/methanol). After washing, the resin was dried under vacuum in a desiccator over $\mathrm{P}_{2} \mathrm{O}_{5}$. All the resins were preswelled in the solvent use in the reaction for 30 minutes before use. Infrared spectra were recorded only on a careful washed and dried resin with $4 \mathrm{~cm}^{-1}$ resolution. More intensive bands are given in $\mathrm{cm}^{-1}$. Known 
compounds $\mathbf{2}^{1}, \mathbf{3}^{2}, \mathbf{5}^{3}, \mathbf{6}^{3}$, were characterized by FTIR, ${ }^{1} \mathrm{H}-\mathrm{NMR}$, and Mass spectrometry and shown to be consistent with the literature compounds.

\section{General procedures to cleave dye (8) from Wang resin.}

Polymer 9 (typically 50-100 mg) was shaken with 80\% TFA in dichloromethane for 24 hours at room temperature. The resin was then filtered, rinsed with 10\% TFA in dichloromethane $(2 \times 5 \mathrm{ml})$, then with dichloromethane $(5 \times 6 \mathrm{ml})$. The filtrate was then evaporated, dried in vacuum for 2 hours and then subjected to ${ }^{1} \mathrm{H}-\mathrm{NMR}$ and mass spectra analysis.

\section{3. ${ }^{1} \mathrm{H}$-NMR, ${ }^{13} \mathrm{C}$-NMR Spectra of compound 8}

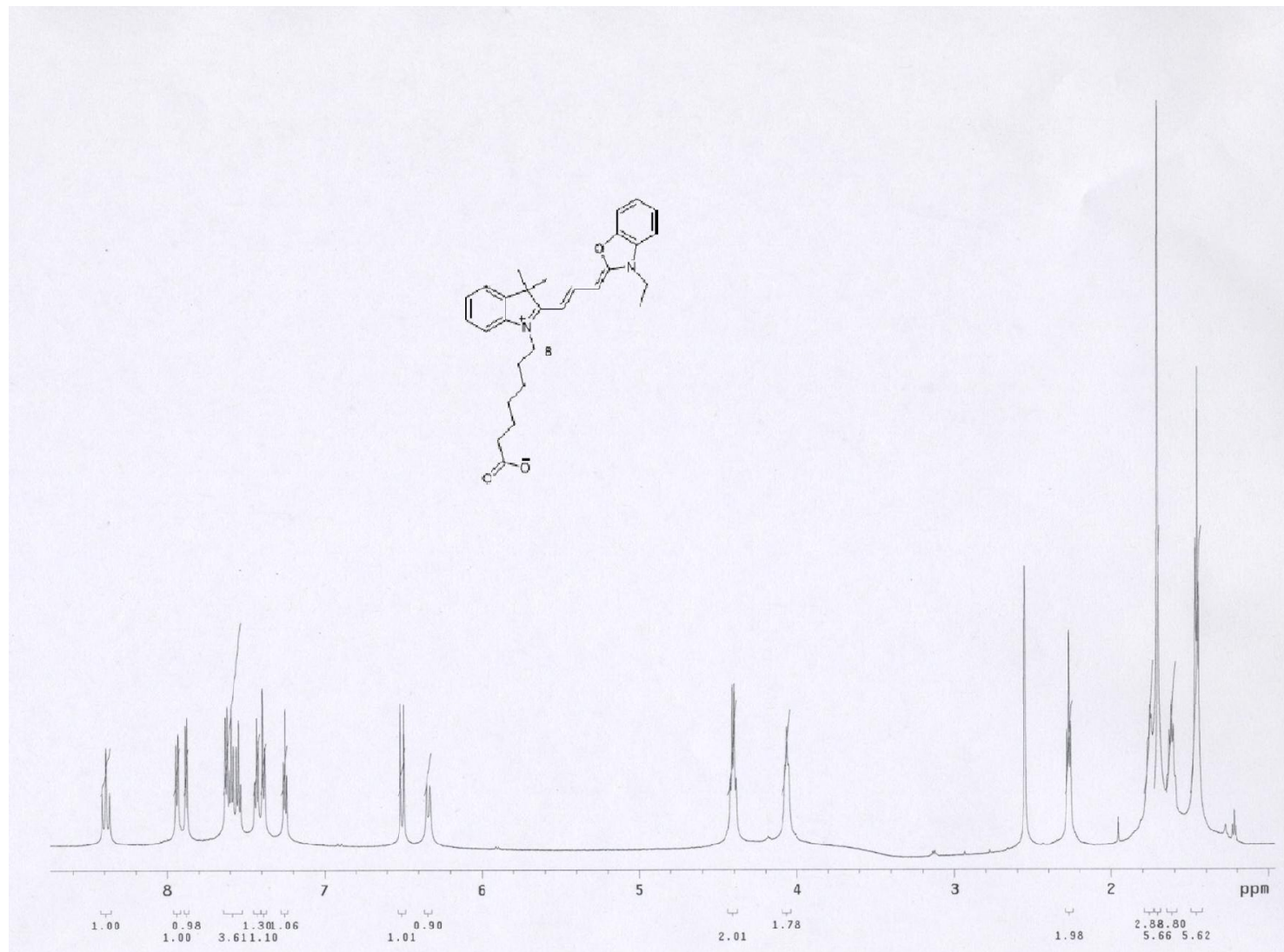

${ }^{1} \mathrm{H}-\mathrm{NMR}\left(600 \mathrm{MHz}\right.$, DMSO- $d_{6}$ ) of dye 8 obtained by method B. 


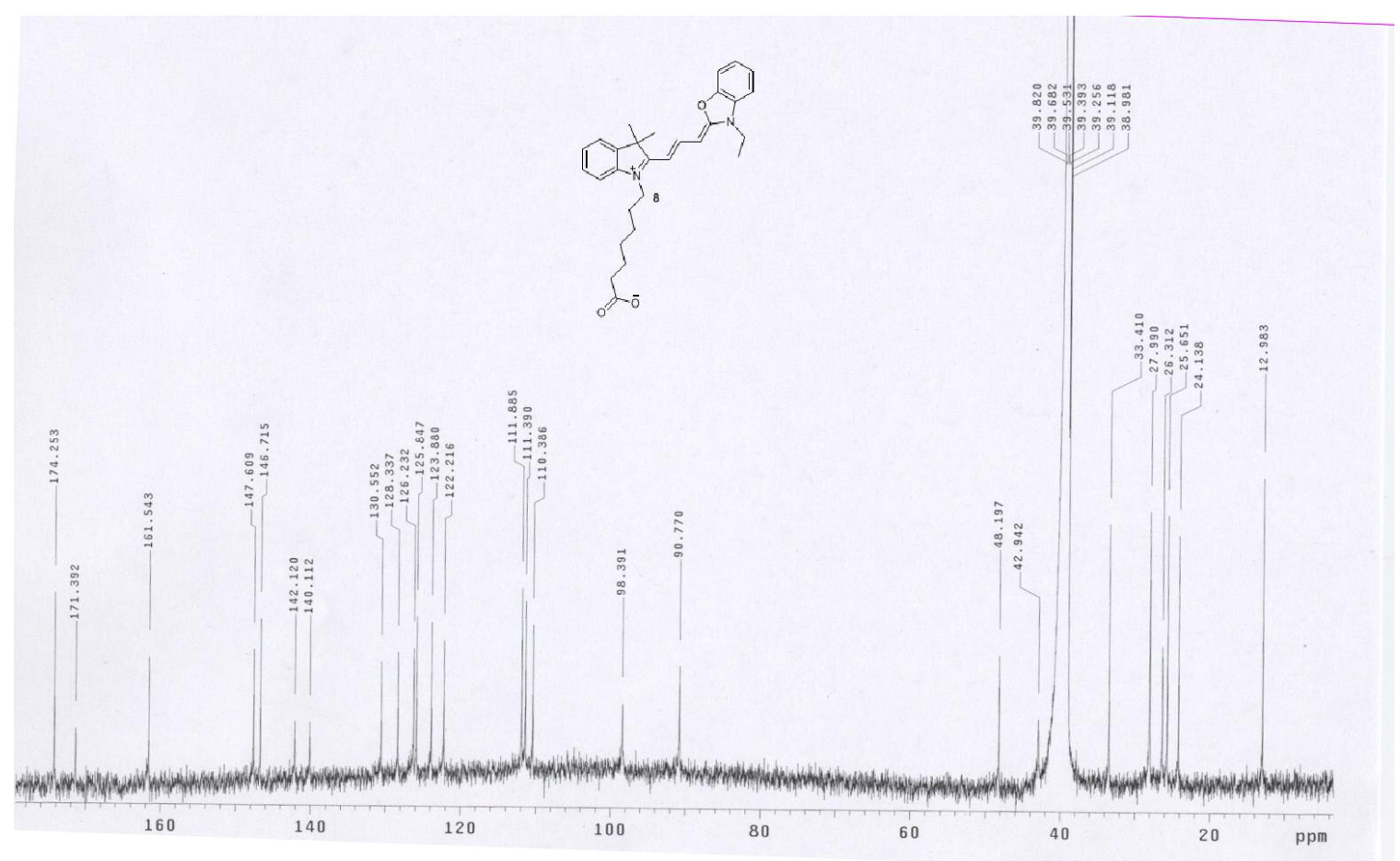

${ }^{13} \mathrm{C}-\mathrm{NMR}\left(150 \mathrm{MHz}\right.$, DMSO- $\left.d_{6}\right)$ of dye $\mathbf{8}$ obtained by method B.

(1) Hamilton A. L.; West R. M.; Cummins W. J.; Briggs M. S. J.; Bruce I. E. Squarate dyes and their use in fluorescent sequencing method. U.S Patent 6,140,494, Oct. 31, 2000.

(2) (a) Braman, J.C. Anderson, J. Fluorescent cyanine dyes and their use in labeling of biomolecules PCT Int. Appl. WO02068537, Sept. 06, 2002; (b) W. J. Cummins, R.M. West, J.A. Smith, Multiply charged cyanine dyes. U.S Patent 6,348,599 B1, Feb. 19, 2002.

(3) R.E.F. Boto, P.F. Santos, L.V. Reis, P. Almeida, Dyes and Pigments 2007, 75, 298-305. 